OPEN ACCESS

Edited by:

Jonathan Paul Richard Scott,

KBRwyle GmbH, Germany

Reviewed by:

Y. Gul Ozkaya

Akdeniz University, Turkey Ginés Viscor

University of Barcelona, Spain

*Correspondence:

Michael Behringer

behringer@sport.uni-frankfurt.de

Specialty section:

This article was submitted to

Exercise Physiology,

a section of the journal

Frontiers in Physiology

Received: 31 October 2018

Accepted: 11 January 2019

Published: 25 January 2019

Citation:

Behringer $M$ and Willberg $C$ (2019) Application of Blood Flow Restriction to Optimize Exercise Countermeasures for Human Space

Flight. Front. Physiol. 10:33. doi: 10.3389/fphys.2019.00033

\section{Application of Blood Flow Restriction to Optimize Exercise Countermeasures for Human Space Flight}

\author{
Michael Behringer* and Christina Willberg \\ Institute of Sports Sciences, Goethe University Frankfurt, Frankfurt, Germany
}

In recent years there has been a strong increase in publications on blood flow restriction (BFR) training. In particular, the fact that this type of training requires only low resistance to induce muscle strength and mass gains, makes BFR training interesting for athletes and scientists alike. For the same reason this type of training is particularly interesting for astronauts working out in space. Lower resistance during training would have the advantage of reducing the risk of strain-induced injuries. Furthermore, strength training with lower resistances would have implications for the equipment required for training under microgravity conditions, as significantly lower resistances have to be provided by the training machines. Even though we are only about to understand the effects of blood flow restriction on exercise types other than low-intensity strength training, the available data indicate that BFR of leg muscles is also able to improve the training effects of walking or running at slow speeds. The underlying mechanisms of BFR-induced functional and structural adaptations are still unclear. An essential aspect seems to be the premature fatigue of Type-I muscle fibers, which requires premature recruitment of Type-II muscle fibers to maintain a given force output. Other theories assume that cell swelling, anabolic hormones, myokines and reactive oxygen species are involved in the mediation of BFR training-related effects. This review article is intended to summarize the main advantages and disadvantages, but also the potential risks of such training for astronauts.

Keywords: human space flight, exercise countermeasure, adaptations to microgravity, BFR training, space adaptations

\section{INTRODUCTION}

Human Spaceflight is still a technical and life science challenge. It is well known, that there are several hazards for the human body in space due to microgravity exposure, radiation, sensory deprivation, the disruption of circadian rhythms as well as the artificial environment (Dayanandan, 2011). In short- and long-term space flights, microgravity has physiological effects on the cardiovascular and musculoskeletal system, solving in compromised aerobic capacity, a decrease of bone density and mineral content as well as muscular atrophy and loss of muscular strength (Widrick et al., 1999; Fitts et al., 2001; Sibonga et al., 2007; Trappe et al., 2009). In order to counteract these changes, special training equipment for use in microgravity was developed and 
used quite early in the history of manned spaceflight. During the 28 - to 84-day Skylab missions in the 1970s, a cycle ergometer was shipped to the international space station (ISS). However, even with a daily training program on the ergometer, the astronauts' maximum oxygen uptake, muscle mass and bone density was decreased on their return from the Skylab missions (Sawin et al., 1976; Vernikos and Schneider, 2010). More recent data indicate that tendon fibers are also adversely affected by prolonged exposure to microgravity (Galloway et al., 2013; McCrum et al., 2018).

Much time has passed since these early Skylab missions and the training equipment for use in microgravity has been continuously refined since then (for review see Loerch, 2015). In the belief that high mechanical forces are required as training stimuli to prevent the musculoskeletal system from being deadapted, a special focus has been placed on the development of exercise devices that can realize these high mechanical forces (Loerch, 2015). As a result of these efforts, astronauts currently have a multifunctional strength training device the Advanced Resistive Exercise Device (ARED) available, which can realize high resistances of up to up to $110 \mathrm{~kg}$ for cable and $270 \mathrm{~kg}$ for bar exercises (Trappe et al., 2009). Since it is well documented that resistance training with moderate to high loads is effective in inducing muscle mass and strength gains both on earth (Garber et al., 2011) and under microgravity conditions (Loehr et al., 2011), the availability of the ARED on the ISS is a major step forward for the maintenance of astronauts' health.

Although, it seems obvious that unloading is best compensated by the application of training stimuli that primarily place mechanical stress on the musculoskeletal system, there is a growing body of evidence, indicating that low-load resistance training also provides a potent training stimulus, when combined with blood flow restriction (BFR) (Kubota et al., 2008; Hackney et al., 2012; Schoenfeld, 2013; Lixandrão et al., 2018). The resistances used in BFR-training averages $30 \%$ of the one repetition maximum (1RM) which is well below the lower limits recommended for strength training (Schoenfeld, 2013). Nevertheless, muscle mass and strength gains induced by BFR-training, are comparable to that of high-intensity training regimen (Loenneke et al., 2012b). For use in microgravity, lower resistances during training would have the advantage of reducing the risk of strain-induced injuries for astronauts (Scheuring et al., 2009; Gabbett, 2016). Furthermore, it would have implications for the equipment required for training under microgravity conditions, as significantly lower resistances have to be provided by the training machines. This would comply with challenges of future space missions as vehicle resources, intra- and extravehicular physical constraints or access to earth-based monitoring (Loerch, 2015). Moreover, BFR has been shown to place a potent, gravitation-like stimulus on the cardiovascular system which may reduce the orthostatic intolerance upon the return to Earth (Iida et al., 2007; Nakajima et al., 2008).

This review article summarizes the possible advantages and disadvantages of BFR training in microgravity to counteract muscle atrophy, discusses the underlying mechanisms, and addresses the question of whether bones and tendons could also benefit from BFR training.

\section{EFFECTS OF MICROGRAVITY ON THE MUSCULOSKELETAL SYSTEM}

Prolonged mechanical unloading is well known to result in a significant de-adaptation of the musculoskeletal system (Lloyd et al., 2014). Muscle atrophy is thought to primarily result from a decreased protein synthesis based on a reduced activation of the IGF1-Akt-mTOR and the FAK-Akt-mTOR pathways (Gao et al., 2018). While the former seems to result from an unloading associated insulin resistance and an impaired insulin-like growth factor (IGF-1) signaling, the latter signaling pathway is directly affected by the elimination of mechanical stress, as the mechanosensitive focal adhesion kinase (FAK) is no longer activated (Graham et al., 2015). Bone loss is mainly driven by an altered differentiation of mesenchymal stem cells by an impaired integrin/mitogen protein kinase pathway due to mitogen-activated protein kinase (MAPK) (Yang et al., 2005). Beside integrins, osteocytes perceive mechanical stress via interstitial fluid, causing a biological cascade which results in $\mathrm{WNt} / \beta$-catenin signaling that triggers bone remodeling (Rochefort and Benhamou, 2013). This and the dysfunction of osteoblasts, expressed due to reduced osteoblast proliferation and activity as well as a reduced cell differentiation lead to an impaired bone formation (Arfat et al., 2014). In comparison to muscle and bone, tendons have so far received little attention regarding adaptation to space flight. However, it is known that tendons adapt to the load that they have to withstand (Vanderby et al., 1990). With the lack of mechanical stress, as it appears in microgravity, proteoglycan and collagen synthesis get inhibited, leading to changes in structure (loss of diameter and density) and in chemical compositions (Johnson et al., 2005).

\section{IN-FLIGHT EXERCISE PROTOCOLS}

In-flight exercise protocols are generally designed to minimize the loss in aerobic capacity, bone, muscle strength and endurance and to counteract neuromuscular dysfunction. The main goal thereby is to maintain in-flight and post-flight performance capabilities of the astronauts (Loehr et al., 2015). Crewmembers are commanded to adhere to their personal exercise protocols, including resistance (ARED) and cardiovascular exercise on a Treadmill or Veloergometer with Vibration Isolation and Stabilization System (TVIS, CEVIS). The training devices save personal data as well as physiological and training parameter, which allows the Mission Control Center (based on Earth) to adjust individual exercise schedules. Since the installation of the ARED in the International Space Station Expedition 18, high resistances can be applied during strength training on the ISS and the device allows about 29 different exercises. However, the ARED is very space-consuming and carries the potential risk of being temporarily unavailable due to technical faults (Hanson 
et al., 2014; Loehr et al., 2015), which motivates the search for and the exploration of smaller and technically simpler devices (Behringer et al., 2016). In addition, high training intensities are associated with an increased risk of injury to the musculoskeletal system (Gabbett, 2016), a fact to be taken seriously, as trainingrelated injuries are the most common source of injury to astronauts on board the ISS (Scheuring et al., 2009). Therefore, the question arises whether BFR training can be a reasonable alternative or supplement for in-flight training sessions. In the following sections, the effects of primarily mechanical stimuli on the musculature are briefly presented and compared with those of more metabolically accentuated stimuli through BFR training.

\section{HIGH MECHANICAL TENSION AS TRAINING STIMULUS FOR MUSCLES, BONES, AND TENDONS}

High mechanical tension is well known as a potent stimulus to trigger muscle growth (Spurway and Wackerhage, 2006; Schoenfeld, 2010), bone mineral accrual (Bolam et al., 2013), and tendon stiffness (Brumitt and Cuddeford, 2015). In case of skeletal muscles, the mechanical forces are converted into intracellular anabolic signals by mechanosensors that are sensitive to the magnitude and the duration of the applied external force (Greenberg et al., 2016). Downstream processes are thought to be regulated by Akt/mTOR pathway (Latres et al., 2005), whereby mechanical tension stimulates mammalian target of rapamycin (mTOR) directly (Hornberger et al., 2006) or $\mathrm{p} 70^{\mathrm{S} 6 \mathrm{~K}}$ is phosphorylated (independent of mTOR) by phosphatidic acid (Lehman et al., 2007). Both pathways increase the protein synthesis of skeletal muscle cells. Furthermore, evidence suggests that mechanical tension activates the mechanosensitive FAK, which upregulates mTOR and thereby the protein synthesis (Chen et al., 1996; Bloch and Gonzalez-Serratos, 2003). However, the fact that high-intensity strength training is often accompanied by neuronal adjustments but only slight increases in muscle growth. Behm (1995) suggests that muscular tension alone cannot be responsible for muscle growth. Beside mechanical tension, stretch, cell swelling, systemic hormonal release, hypoxia, muscle damage, and ROS production are discussed as further reasons, activating anabolic signaling in skeletal muscle cells (Spurway and Wackerhage, 2006; Ozaki et al., 2015; de Freitas et al., 2017).

High mechanical forces placed on the musculoskeletal system result in bone matrix deformations inducing shear stress by bone fluid perturbations and cell membrane deformations through tethering elements of the glycocalyx (Bonewald and Johnson, 2008). Fluid flow, as well as intramedullary pressure are supposed to be influenced by mechanical loading, as well as vascular blood pressure, resulting in changing anabolic stimuli (Qin et al., 2003; Stevens et al., 2006). This mechanical stress is sensed by osteocytes (sensor cells) that transmit the signal to osteoblasts and osteoclasts (effector cells), ultimately stimulating bone formation on both, trabecular and cortical bone (Fujimura et al., 1997; Mi et al., 2005; Fritton and
Weinbaum, 2009). Evidence is given, that biomarkers of bone formation like osteocalcin or bone-specific alkaline phosphatase (B-ALP) are increased after resistance training. Especially high training loads correlate with this response (Fujimura et al., 1997; Hu et al., 2011). However, since bone cells rapidly desensitize from mechanical stimuli intermittent loading regimens are necessary to allow for a resensitization of mechanoreceptors (Robling et al., 2002a,b; Saxon et al., 2005). Recent investigations expect the wingless-type (Wnt)/ $\beta$-catenin canonical signaling pathway to be an important regulator in this process (Rochefort and Benhamou, 2013). While in osteoblasts, this pathway is crucial for synthesis, proliferation, and differentiation of the bone matrix, it enables osteocytes to transmit the sensed mechanical signals to cells on the bone surface.

Similar to the mechanisms in muscles and bones, mechanical tension in the tendon leads to the activation of mechanotransduction pathways, causing anabolic tissue responses (Arampatzis et al., 2009). Depending on the duration, frequency and intensity of the mechanical stimulus, the matrix protein synthesis, the expression and arrangement of collagen fibers as well as the expression of proteoglycans are adapted (Arampatzis et al., 2007). According to Arampatzis et al. (2007), the applied mechanical tension needs to exceed a certain threshold to induce adaptations of mechanical and morphological properties. This is supported by Kubo et al. (2006), who found that high- but not low-load isokinetic training of the knee extensors increased the stiffness of the vastus lateralis tendon-aponeurosis.

\section{METABOLIC STRESS AS AN ANABOLIC SIGNAL FOR THE MUSCULATURE}

The mechanisms underlying the BFR-mediated muscle mass and strength gains still remain unclear. Since the mechanical load during this type of resistance training is low, it is assumed that the metabolic stress is primarily responsible for the induced adaptations. This is supported by the observation of Takada et al. (2012) who reported that hypertrophy and strength gains were correlated with the decrease of the intramuscular $\mathrm{pH}$ (hypertrophy: $r=0.80$; strength gains: $r=0.65$ ) and the accumulation of inorganic phosphate (hypertrophy: $r=0.88$; strength gains: $r=0.60)$ during low-intensity (20\% 1RM) BFRtraining.

BFR-associated metabolic stress is a consequence of decreased oxygen supply caused by reduced blood flow (Kon et al., 2012), resulting in an impairment of the aerobic metabolism and premature fatigue of the aerobic slow-twitch fibers (Scott et al., 2014). Despite low external loads, the skeletal muscle is forced under these conditions to recruit fast-twitching muscle fibers to maintain force output, which further aggravates the accumulation of metabolites (Loenneke et al., 2011a). The accumulated metabolites are thought to provoke a reflex inhibition of alpha-motoneurons via type III and IV afferents resulting in a further increase of type II motor unit recruitment 
(Scott et al., 2014). Some authors see the recruitment of fasttwitch fibers as one of the central mechanisms by which BFR can trigger hypertrophy (Pope et al., 2013; Pearson and Hussain, 2015). Others believe that the acute release of anabolic hormones such as the human growth hormone (Abe et al., 2012; Pope et al., 2013; Park et al., 2015) or IGF-1 (Loenneke et al., 2011a; Scott et al., 2014; Park et al., 2015; Pearson and Hussain, 2015) contributes significantly to the BFR-mediated effects on muscle growth. The release of growth hormone appears to be associated with metabolic stress via the metaboreflex. This reflex is caused by locally accumulated metabolites activating metaboreceptors, which in turn activate the hypothalamicpituitary axis via type III and IV afferents (Inagaki et al., 2011). Acute releases of catecholamines (e.g., norephrine response) have also been discussed as a factor for the exercise induced protein synthesis (Pope et al., 2013). However, several researchers have questioned the role of such acute exercise-induced hormone releases for muscle hypertrophy (Loenneke et al., 2012c; Pope et al., 2013).

The accumulation of osmotically active metabolites as lactate further leads to swelling of the muscle fibers as fluid shifts from the extra- to the intracellular space to equilibrate the osmotic gradient (Schoenfeld and Contreras, 2014). The resulting intracellular pressure is sensed by integrin-associated, cellintrinsic volume sensors that activate mTOR and MAPK pathways, by which cell swelling is thought to trigger the muscular protein synthesis (Low et al., 1997; Abe et al., 2012; Pearson and Hussain, 2015). Kim et al. (2017) hypothesize that this muscle cell swelling induced pathway is one of the key mechanisms by which low-intensity BFR-training is able to induce anabolic effects (Loenneke et al., 2012a).

Another mechanism that could support BFR training induced muscle growth is the effect of reactive hyperemia on the vascular system. Two-fold increases in blood flow after BFR training over a period of more than $1 \mathrm{~h}$ have been reported (Gundermann et al., 2012). It is assumed that this long-lasting shear stimulus is responsible for the improved dilatory capacity of resistance vessels following BFR-Training (Hunt, 2014). In addition, BFR training increases microvascular filtration capacity as a sign of increased capillarization (Evans et al., 2010). Since adequate perfusion of the muscle fibers is crucial for muscle growth (Snijders et al., 2017), BFR-associated hyperemia with its effects on the vascular system could be an important factor supporting training-induced hypertrophy.

Furthermore, the ischemic conditions due to BFR lead to an upregulation of endothelial NOS, mRNA, and hypoxia inducible factor $1 \alpha$ (HIF-1 $\alpha$ ), which influence autocrine factors (IGF-1) and satellite cell activation and thus, lead to increased protein synthesis (Pope et al., 2013; Pearson and Hussain, 2015). There are also some investigations that consider reactive oxygen species, increased glycogen storage or reduced myostatin to be influencing factors for muscle protein synthesis (Pope et al., 2013; Pearson and Hussain, 2015). However, there is no clear evidence for those factors. For example, it is well known that ROS production increases when blood supply returns (reperfusion) after sustained ischemia (Korthuis et al., 1985; Tsutsumi et al., 2007). Based on these observations, it could be assumed that the BFR-associated ischemia-reperfusion sequence exacerbates the hypoxic signaling cascade (dependent on HIF-1 $\alpha$ ). However, the data available so far often show no increase in ROS as a result of BFR training (Goldfarb et al., 2008; Rozales Ramis et al., 2017), so that the question of usefulness of antioxidant administration cannot yet be conclusively clarified.

\section{EFFECTS OF LOW-INTENSITY BFR-TRAINING ON BONE HEALTH}

The majority of available literature on BFR training has dealt with its effects on skeletal muscle fibers, while only a few studies have investigated the effects on other tissues of the musculoskeletal system. However, some evidence is available that low-intensity BFR-training positively affects bone metabolism, formation and resorption (Bittar et al., 2018). Increased intramedullary pressure and interstitial fluid flow within the bone, caused by vascular occlusion, are hypothesized to be the main mechanisms affecting bone remodeling (Loenneke et al., 2012d). The effectiveness of BFR as a countermeasure for the bone loss was investigated by an increase of B-ALP, which is considered to display the activity of osteoblasts (Beekley et al., 2005). Further, bone resorption markers as C-terminal cross-linking telopeptide of type I collagen (CTX/NTX) has been reported to be decreased after BFR exercise (Bemben et al., 2007). Karabulut et al. (2011), who compared serum concentrations of bone markers in older man following high-intensity resistance training and low-intensity BFR-training, found B-ALP and B-ALP to CTX ratio improved after both training protocols. Although these results indicate that high mechanical loads are not necessary to prevent bone loss in microgravity, further research is needed to develop a better understanding of the BFR-training mediated effects.

\section{EFFECTS OF LOW-INTENSITY BFR-TRAINING ON TENDONS}

There is some evidence that hypoxic conditions improve the proliferation of human tendon stem cells, when compared to normoxic conditions (Lee et al., 2012; Millar et al., 2012; Huang et al., 2013; Zhang and Wang, 2013; Jiang et al., 2014). Furthermore, hypoxia has been reported to be essential for the healing of the bone-tendon junction in which HIF- $1 \alpha$ plays a key role (Zhao et al., 2011). Although, there are studies that have used BFR training in the rehabilitation of tendon injuries, the researchers' main aim in those studies was to use BFR training to reduce the required training intensity to improve muscle strength (Yow et al., 2018). To the best of the authors' knowledge, only few data are available regarding the effects of BFR training on the structure and function of tendons. In one study, Mohmara et al. (2014) investigated the effect of lowintensity (30\% 1RM) leg-calf-raises either with or without BFR on the Achilles tendon thickness. The authors found no difference in tendon thickness between both conditions immediately and 
$24 \mathrm{~h}$ after the exercise protocol. However, this acute reaction does not provide any information about chronic tendon adaptations to BFR training programs. Kubo et al. (2006) reported that a 12-week resistance training (3 days/week) improved the stiffness of tendon-aponeurosis complex in the vastus lateralis only in the high-intensity $(80 \% 1 \mathrm{RM})$ but not in the low-intensity $(20 \%$ 1RM) BFR group. Thus, according to the available literature it seems that high-mechanical forces cannot be dispensed with, if adaptations of the tendons are wanted. However, the data available on this topic are still very weak, so that further studies are required in order to be able to make reliable statements on this issue.

\section{POTENTIAL RISK FACTORS OF BFR IN SPACE}

The risk of negative side effects of BFR-training has already been reviewed by others, whereby bruising under the cuffs (13.1\%) due to the applied cuff pressure was most common (see, Loenneke et al., 2011b). In this regard, there is some disunity about the required cuff pressure and width for an optimal training response with as little vascular stress as possible. However, due to the potential side effects, there is broad agreement that individual cuff pressures should be preferred over fixed cuff pressures (Cook et al., 2007; Clark et al., 2011). Furthermore, there is some evidence that low cuff pressures $(\sim 50 \%$ of the individual occlusion pressure) are sufficient to provoke the desired BFRmediated effects on the musculoskeletal system and reduces the risk for negative side effects associated with higher pressures near arterial occlusion decrease (Loenneke et al., 2014a). Based on these arguments, it becomes clear that the measurement of the individual occlusion pressure of the astronauts is necessary to standardize the pressure of the cuff. Given the fact that blood pressure behaves differently under microgravity conditions (Norsk, 2014), pre-flight measurements are unsuitable for determining the individual occlusion pressure for training in space. Fortunately, BFR equipment is now available that automatically measures the individual closing pressure and adjusts the cuff pressure for the training accordingly. It is also conceivable that BFR training damages the muscles distal to the cuff. However, the small increase in muscle damage markers after BFR training speaks against this assumption (Loenneke et al., 2014b). One reason for the low level of damage is certainly the use of low resistance in this training method. Apparently, however, the induced ischemia is also not strong enough to have a direct or indirect (via. reperfusion injury) damaging effect on the muscle tissue (Thiebaud et al., 2013; Loenneke et al., 2014b). Reperfusion injury is caused by completely occluded blood flow to a limb, whereas the intensity and duration are pivotal role. In muscle tissue, irreversible damage can be seen after $4-6 \mathrm{~h}$ of occlusion (Blaisdell, 2002) and therefore the injury risk during BFR training is considered to be low. Nevertheless, there are also a few contradictory findings. Some authors reported that BFR increased the perceived muscle soreness as well as the sarcolemma permeability (Wernbom et al., 2012) and reduced the endothelial function (Renzi et al., 2010). In summary, however, the majority of the data indicate that the risk of muscle damage from BFR training is low.

Another common concern is the coagulation of blood and formation of thrombi by the BFR-induced disturbance of the laminar blood flow. Surprisingly, however, fibrinolytic activity has been reported to be increased after BFR training and the incidence of thrombosis to be lower compared to the general population (Nakajima et al., 2006). Other cardiovascular risk factors of BFR training are related to the decreased venous blood return to the heart. As a consequence, the heart rate and blood pressure increase to maintain cardiac output (Takano et al., 2005). This might be an important risk factor for people with an increased predisposition to cardiovascular disease. However, since astronauts are under strict medical supervision and are only allowed to fly into space if pre-flight medical examinations have been passed, this risk appears to be low for astronauts.

\section{CONCLUSION}

Microgravity exposure has degenerative effects on the musculoskeletal system. Regarding further long duration flights like future Mars Expeditions, there is a need to tweak existing exercise protocols, to gain maximum training effects by using minimal equipment. Low load BFR-training allows for muscle mass and strength gains without the risk of injury associated with high resistances. Additionally, some evidence is available that bone mass and density can be increased by BFR exercise.

Despite the numerous positive findings on low-intensity strength training with BFR, it should be noted that these data were collected under normobaric and normoxic conditions. Therefore, future studies should clarify whether a hypobaric hypoxia (as may occur on board of future Mars Expeditions) or blood redistribution caused by weightlessness has an influence on BFR training results. It seems plausible that under these conditions lower cuff pressures are sufficient to trigger the effects of BFR training.

The low resistances required to achieve these goals also have an advantage regarding the equipment. Exercise devices would have to provide lower resistances, which facilitates their construction and preserves the vehicle capacity. Unfortunately, to date very little data are available whether low-intensity BFRtraining is able to avoid the unloading associated deterioration of tendons. Nevertheless, the results of the review clearly show that BFR training is a useful supplement to training in microgravity.

Future studies are needed to investigate whether the blood redistribution caused by weightlessness has an influence on BFR training results. Therefore, long-term, $6^{\circ}$ head down tilt bed rest studies investigating BFR-training should be sought to evaluate physiological adaptations of the musculoskeletal system.

\section{AUTHOR CONTRIBUTIONS}

$\mathrm{MB}$ and $\mathrm{CW}$ did the research for this topic, the framework and structure of this article, and discussed the possible effects. 


\section{REFERENCES}

Abe, T., Loenneke, J. P., Fahs, C. A., Rossow, L. M., Thiebaud, R. S., and Bemben, M. G. (2012). Exercise intensity and muscle hypertrophy in blood flowrestricted limbs and non-restricted muscles: a brief review. Clin. Physiol. Funct. Imaging 32, 247-252. doi: 10.1111/j.1475-097X.2012.01126.X

Arampatzis, A., Karamanidis, K., and Albracht, K. (2007). Adaptational responses of the human achilles tendon by modulation of the applied cyclic strain magnitude. J. Exp. Biol. 210, 2743-2753. doi: 10.1242/jeb.003814

Arampatzis, A., Karamanidis, K., Mademli, L., and Albracht, K. (2009). Plasticity of the human tendon to short- and long-term mechanical loading. Exerc. Sport Sci. Rev. 37, 66-72. doi: 10.1097/JES.0b013e31819c2e1d

Arfat, Y., Xiao, W. Z., Iftikhar, S., Zhao, F., Li, D. J., Sun, Y. L., et al. (2014). Physiological effects of microgravity on bone cells. Calcif. Tissue Int. 94, 569579. doi: 10.1007/s00223-014-9851-x

Beekley, M. D., Sato, Y., and Abe, T. (2005). KAATSU-walk training increases serum bone-specific alkaline phosphatase in young men. Int. J. Kaatsu Train. Res. 1, 77-81. doi: 10.3806/ijktr.1.77

Behm, D. G. (1995). Neuromuscular implications and applications of resistance training. J. Strength Cond. Res. 9, 264-274. doi: 10.1519/00124278-19951100000014

Behringer, M., Schüren, T., McCourt, M., and Mester, J. (2016). Efficacy of manual versus free-weight training to improve maximal strength and performance for microgravity conditions. J. Sports Sci. 34, 630-636. doi: 10.1080/02640414.2015. 1066025

Bemben, D. A., Palmer, I. J., Abe, T., Sato, Y., and Bemben, M. G. (2007). Effects of a single bout of low intensity KAATSU resistance training on markers of bone turnover in young men. Int. J. Kaatsu Train. Res. 3, 21-26. doi: 10.3806/ ijktr.3.21

Bittar, S. T., Pfeiffer, P. S., Santos, H. H., and Cirilo-Sousa, M. S. (2018). Effects of blood flow restriction exercises on bone metabolism: a systematic review. Clin. Physiol. Funct. Imaging 38, 930-935. doi: 10.1111/cpf.12512

Blaisdell, F. W. (2002). The pathophysiology of skeletal muscle ischemia and the reperfusion syndrome: a review. Cardiovasc. Surg. 10, 620-630. doi: 10.1016/ S0967-2109(02)00070-4

Bloch, R. J., and Gonzalez-Serratos, H. (2003). Lateral force transmission across costameres in skeletal muscle. Exerc. Sport Sci. Rev. 31, 73-78. doi: 10.1097/ 00003677-200304000-00004

Bolam, K. A., van Uffelen, J. G. Z., and Taaffe, D. R. (2013). The effect of physical exercise on bone density in middle-aged and older men: a systematic review. Osteoporos. Int. 24, 2749-2762. doi: 10.1007/s00198-013-2346-1

Bonewald, L. F., and Johnson, M. L. (2008). Osteocytes, mechanosensing and Wnt signaling. Bone 42, 606-615. doi: 10.1016/j.bone.2007.12.224

Brumitt, J., and Cuddeford, T. (2015). Current concepts of muscle and tendon adaptation to strength and conditioning. Int. J. Sports Phys. Ther. 10, $748-759$.

Chen, H. C., Appeddu, P. A., Isoda, H., and Guan, J. L. (1996). Phosphorylation of tyrosine 397 in focal adhesion kinase is required for binding phosphatidylinositol 3-kinase. J. Biol. Chem. 271, 26329-26334. doi: 10.1074/jbc.271.42.26329

Clark, B. C., Manini, T. M., Hoffman, R. L., Williams, P. S., Guiler, M. K., Knutson, M. J., et al. (2011). Relative safety of 4 weeks of blood flow-restricted resistance exercise in young, healthy adults: blood flow restricted exercise. Scand. J. Med. Sci. Sports 21, 653-662. doi: 10.1111/j.1600-0838.2010.01100.x

Cook, S. B., Clark, B. C., and Ploutz-Snyder, L. L. (2007). Effects of exercise load and blood-flow restriction on skeletal muscle function. Med. Sci. Sports Exerc. 39, 1708-1713. doi: 10.1249/mss.0b013e31812383d6

Dayanandan, P. (2011). Gravitational biology and space life sciences: current status and implications for the Indian space programme. J. Biosci. 36, 911-919. doi: 10.1007/s12038-011-9150-x

de Freitas, M. C., Gerosa-Neto, J., Zanchi, N. E., Lira, F. S., and Rossi, F. E. (2017). Role of metabolic stress for enhancing muscle adaptations: practical applications. World J. Methodol. 7, 46-54. doi: 10.5662/wjm.v7.i2.46

Evans, C., Vance, S., and Brown, M. (2010). Short-term resistance training with blood flow restriction enhances microvascular filtration capacity of human calf muscles. J. Sports Sci. 28, 999-1007. doi: 10.1080/02640414.2010.485647

Fitts, R. H., Riley, D. R., and Widrick, J. J. (2001). Functional and structural adaptations of skeletal muscle to microgravity. J. Exp. Biol. 204, 3201-3208.
Fritton, S. P., and Weinbaum, S. (2009). Fluid and solute transport in bone: flowinduced mechanotransduction. Annu. Rev. Fluid Mech. 41, 347-374. doi: 10. 1146/annurev.fluid.010908.165136

Fujimura, R., Ashizawa, N., Watanabe, M., Mukai, N., Amagai, H., Fukubayashi, T., et al. (1997). Effect of resistance exercise training on bone formation and resorption in young male subjects assessed by biomarkers of bone metabolism. J. Bone Miner. Res. 12, 656-662. doi: 10.1359/jbmr.1997.12.4.656

Gabbett, T. J. (2016). The training-injury prevention paradox: should athletes be training smarter and harder? Br. J. Sports Med. 50, 273-280. doi: 10.1136/ bjsports-2015-095788

Galloway, M. T., Lalley, A. L., and Shearn, J. T. (2013). The role of mechanical loading in tendon development, maintenance, injury, and repair. J. Bone Joint Surg. Am. 95, 1620-1628. doi: 10.2106/JBJS.L.01004

Gao, Y., Arfat, Y., Wang, H., and Goswami, N. (2018). Muscle atrophy induced by mechanical unloading: mechanisms and potential countermeasures. Front. Physiol. 9:235. doi: 10.3389/fphys.2018.00235

Garber, C. E., Blissmer, B., Deschenes, M. R., Franklin, B. A., Lamonte, M. J., Lee, I. M., et al. (2011). Quantity and quality of exercise for developing and maintaining cardiorespiratory, musculoskeletal, and neuromotor fitness in apparently healthy adults: guidance for prescribing exercise. Med. Sci. Sports Exerc. 43, 1334-1359. doi: 10.1249/MSS.0b013e318213fefb

Goldfarb, A. H., Garten, R. S., Chee, P. D. M., Cho, C., Reeves, G. V., Hollander D. B., et al. (2008). Resistance exercise effects on blood glutathione status and plasma protein carbonyls: influence of partial vascular occlusion. Eur. J. Appl. Physiol. 104, 813-819. doi: 10.1007/s00421-008-0836-1

Graham, Z. A., Gallagher, P. M., and Cardozo, C. P. (2015). Focal adhesion kinase and its role in skeletal muscle. J. Muscle Res. Cell Motil. 36, 305-315. doi: 10.1007/s10974-015-9415-3

Greenberg, M. J., Arpağ, G., Tüzel, E., and Ostap, E. M. (2016). A perspective on the role of myosins as mechanosensors. Biophys. J. 110, 2568-2576. doi: 10.1016/j.bpj.2016.05.021

Gundermann, D. M., Fry, C. S., Dickinson, J. M., Walker, D. K., Timmerman, K. L., Drummond, M. J., et al. (2012). Reactive hyperemia is not responsible for stimulating muscle protein synthesis following blood flow restriction exercise. J. Appl. Physiol. 112, 1520-1528. doi: 10.1152/japplphysiol.01267.2011

Hackney, K. J., Everett, M., Scott, J. M., and Ploutz-Snyder, L. (2012). Blood flowrestricted exercise in space. Extrem. Physiol. Med. 1:12. doi: 10.1186/2046-7648$1-12$

Hanson, A., Perters, B., Caldwell, B., Sinka, J., Kreutzburg, G., and Ploutz-Synder, L. (2014). "Portable load measurement device for use during ARED exercise on ISS," in Paper Presented at the Human Research Program Investigators Workshop 2014, Galveston, TX.

Hornberger, T. A., Chu, W. K., Mak, Y. W., Hsiung, J. W., Huang, S. A., and Chien, S. (2006). The role of phospholipase D and phosphatidic acid in the mechanical activation of MTOR signaling in skeletal muscle. Proc. Natl. Acad. Sci. U.S.A. 103, 4741-4746. doi: 10.1073/pnas.0600678103

Hu, M., Finni, T., Xu, L., Zou, L., and Cheng, S. (2011). Effects of resistance training on biomarkers of bone formation and association with red blood cell variables. J. Physiol. Biochem. 67, 351-358. doi: 10.1007/s13105-011-0082-6

Huang, T.-F., Yew, T. L., Chiang, E. R., Ma, H. L., Hsu, C. Y., Hsu, S. H., et al. (2013). Mesenchymal stem cells from a hypoxic culture improve and engraft achilles tendon repair. Am. J. Sports Med. 41, 1117-1125. doi: 10.1177/ 0363546513480786

Hunt, J. (2014). The Impact of Blood Flow Restricted Exercise on the Peripheral Vasculature. Available at: https://dspace.lboro.ac.uk/dspace-jspui/handle/2134/ 14595

Iida, H., Kurano, M., Takano, H., Kubota, N., Morita, T., Meguro, K., et al. (2007). Hemodynamic and neurohumoral responses to the restriction of femoral blood flow by KAATSU in healthy subjects. Eur. J. Appl. Physiol. 100, 275-285. doi: 10.1007/s00421-007-0430-y

Inagaki, Y., Madarame, H., Neya, M., and Ishii, N. (2011). Increase in serum growth hormone induced by electrical stimulation of muscle combined with blood flow restriction. Eur. J. Appl. Physiol. 111, 2715-2721. doi: 10.1007/s00421-0111899-y

Jiang, D., Jiang, Z., Zhang, Y., Wang, S., Yang, S., Xu, B., et al. (2014). Effect of young extrinsic environment stimulated by hypoxia on the function of aged tendon stem cell. Cell Biochem. Biophys. 70, 967-973. doi: 10.1007/s12013-0140004-7 
Johnson, R. B., Tsao, A. K., St John, K. R., Betcher, R. A., Tucci, M. A., and Benghuzzi, H. A. (2005). Effects of spaceflight on the attachment of tendons to bone in the hindlimb of the pregnant rat. Anat. Rec. Part A Discov. Mol. Cell. Evol. Biol. 282A, 147-156. doi: 10.1002/ar.a.20139

Karabulut, M., Bemben, D. A., Sherk, V. D., Anderson, M. A., Abe, T., and Bemben, M. G. (2011). Effects of high-intensity resistance training and low-intensity resistance training with vascular restriction on bone markers in older men. Eur. J. Appl. Physiol. 111, 1659-1667. doi: 10.1007/s00421-010-1796-9

Kim, D., Loenneke, J. P., Ye, X., Bemben, D. A., Beck, T. W., Larson, R. D., et al. (2017). Low-load resistance training with low relative pressure produces muscular changes similar to high-load resistance training. Muscle Nerve 56, E126-E133. doi: 10.1002/mus.25626

Kon, M., Ikeda, T., Homma, T., and Suzuki, Y. (2012). Effects of low-intensity resistance exercise under acute systemic hypoxia on hormonal responses. J. Strength Cond. Res. 26, 611-617. doi: 10.1519/JSC.0b013e3182281c69

Korthuis, R. J., Granger, D. N., Townsley, M. I., and Taylor, A. E. (1985). The role of oxygen-derived free radicals in ischemia-induced increases in canine skeletal muscle vascular permeability. Circ. Res. 57, 599-609. doi: 10.1161/01.RES.57. 4.599

Kubo, K., Komuro, T., Ishiguro, N., Tsunoda, N., Sato, Y., Ishii, N., et al. (2006). Effects of low-load resistance training with vascular occlusion on the mechanical properties of muscle and tendon. J. Appl. Biomech. 22, 112-119. doi: $10.1123 /$ jab.22.2.112

Kubota, N., Takano, H., Tsutsumi, T., Kurano, M., Iida, H., Yasuda, T., et al. (2008). Resistance exercise combined with KAATSU during simulated weightlessness. Int. J. Kaatsu Train. Res. 4, 9-15. doi: 10.3806/ijktr.4.9

Latres, E., Amini, A. R., Amini, A. A., Griffiths, J., Francis Martin, J., Wei, Y., et al. (2005). Insulin-like growth factor-1 (IGF-1) inversely regulates atrophyinduced genes via the phosphatidylinositol 3-kinase/Akt/mammalian target of rapamycin (PI3K/Akt/MTOR) pathway. J. Biol. Chem. 280, 2737-2744. doi: 10.1074/jbc.M407517200

Lee, W. Y. W., Lui, P. P. Y., and Rui, Y. F. (2012). Hypoxia-mediated efficient expansion of human tendon-derived stem cells in vitro. Tissue Eng. Part A 18, 484-498. doi: 10.1089/ten.tea.2011.0130

Lehman, N., Ledford, B., Di Fulvio, M., Frondorf, K., McPhail, L. C., and GomezCambronero, J. (2007). Phospholipase D2-derived phosphatidic acid binds to and activates ribosomal P70 S6 kinase independently of MTOR. FASEB J. 21, 1075-1087. doi: 10.1096/fj.06-6652com

Lixandrão, M. E., Ugrinowitsch, C., Berton, R., Vechin, F. C., Conceição, M. S., Damas, F., et al. (2018). Magnitude of muscle strength and mass adaptations between high-load resistance training versus low-load resistance training associated with blood-flow restriction: a systematic review and meta-analysis. Sports Med. 48, 361-378. doi: 10.1007/s40279-017-0795-y

Lloyd, S. A., Lang, C. H., Zhang, Y., Paul, E. M., Laufenberg, J., Lewis, G. S., et al. (2014). Interdependence of muscle atrophy and bone loss induced by mechanical unloading. J. Bone Miner. Res. 29, 1118-1130. doi: 10.1002/jbmr. 2113

Loehr, J. A., Guilliams, M. E., Petersen, N., Hirsch, N., Kawashima, S., and Ohshima, H. (2015). Physical training for long-duration spaceflight. Aerosp. Med. Hum. Perform. 86, 14-23. doi: 10.3357/AMHP.EC03.2015

Loehr, J. A., Lee, S. M., English, K. L., Sibonga, J., Smith, S. M., Spiering, B. A., et al. (2011). Musculoskeletal adaptations to training with the advanced resistive exercise device. Med. Sci. Sports Exerc. 43, 146-156. doi: 10.1249/MSS. 0b013e3181e4f161

Loenneke, J. P., Fahs, C. A., Rossow, L. M., Abe, T., and Bemben, M. G. (2012a). The anabolic benefits of venous blood flow restriction training may be induced by muscle cell swelling. Med. Hypotheses 78, 151-154. doi: 10.1016/j.mehy.2011. 10.014

Loenneke, J. P., Wilson, J. M., Marín, P. J., Zourdos, M. C., and Bemben, M. G. (2012b). Low intensity blood flow restriction training: a meta-analysis. Eur. J. Appl. Physiol. 112, 1849-1859. doi: 10.1007/s00421-011-2167-x

Loenneke, J. P., Wilson, J. M., Thiebaud, R. S., Abe, T., Lowery, R. P., and Bemben, M. G. (2012c). B2 adrenoceptor signaling-induced muscle hypertrophy from blood flow restriction: is there evidence? Horm. Metab. Res. 44, 489-493. doi: 10.1055/s-0032-1314787

Loenneke, J. P., Young, K. C., Fahs, C. A., Rossow, L. M., Bemben, D. A., and Bemben, M. G. (2012d). Blood flow restriction: rationale for improving bone. Med. Hypotheses 78, 523-527. doi: 10.1016/j.mehy.2012.01.024
Loenneke, J. P., Fahs, C. A., Wilson, J. M., and Bemben, M. G. (2011a). Blood flow restriction: the metabolite/volume threshold theory. Med. Hypotheses 77, 748-752. doi: 10.1016/j.mehy.2011.07.029

Loenneke, J. P., Wilson, J. M., Wilson, G. J., Pujol, T. J., and Bemben, M. G. (2011b). Potential safety issues with blood flow restriction training: safety of blood flowrestricted exercise. Scand. J. Med. Sci. Sports 21, 510-518. doi: 10.1111/j.16000838.2010.01290.x

Loenneke, J. P., Thiebaud, R. S., Abe, T., and Bemben, M. G. (2014a). Blood flow restriction pressure recommendations: the hormesis hypothesis. Med. Hypotheses 82, 623-626. doi: 10.1016/j.mehy.2014.02.023

Loenneke, J. P., Thiebaud, R. S., and Abe, T. (2014b). Does blood flow restriction result in skeletal muscle damage? A critical review of available evidence. Scand. J. Med. Sci. Sports 24, e415-e422. doi: 10.1111/sms.12210

Loerch, L. H. (2015). Exercise countermeasures on ISS: summary and future directions. Aerosp. Med. Hum. Perform. 86, 92-94. doi: 10.3357/AMHP.EC12. 2015

Low, S. Y., Rennie, M. J., and Taylor, P. M. (1997). Signaling elements involved in amino acid transport responses to altered muscle cell volume. FASEB J. 11, 1111-1117. doi: 10.1096/fasebj.11.13.9367345

McCrum, C., Leow, P., Epro, G., König, M., Meijer, K., and Karamanidis, K. (2018). Alterations in leg extensor muscle-tendon unit biomechanical properties with ageing and mechanical loading. Front. Physiol. 9:150. doi: 10.3389/fphys.2018. 00150

Mi, L. Y., Basu, M., Fritton, S. P., and Cowin, S. C. (2005). Analysis of avian bone response to mechanical loading, part two: development of a computational connected cellular network to study bone intercellular communication. Biomech. Model. Mechanobiol. 4, 132-146. doi: 10.1007/s10237-004-0066-3

Millar, N. L., Reilly, J. H., Kerr, S. C., Campbell, A. L., Little, K. J., Leach, W. J., et al. (2012). Hypoxia: a critical regulator of early human tendinopathy. Ann. Rheum. Dis. 71, 302-310. doi: 10.1136/ard.2011.154229

Mohmara, Y. A., Chulvi-Medrano, I., de Marcos, D. G., Granell, J. C., and Martinez, J. B. (2014). 5 effects of low-intensity concentric combined with blood flow restriction on achilles tendon. Br. J. Sports Med. 48(Suppl. 2), A3-A4. doi: 10.1136/bjsports-2014-094114.5

Nakajima, T., Iida, H., Kurano, M., Takano, H., Morita, T., Meguro, K., et al. (2008). Hemodynamic responses to simulated weightlessness of 24-h head-down bed rest and KAATSU blood flow restriction. Eur. J. Appl. Physiol. 104, 727-737. doi: 10.1007/s00421-008-0834-3

Nakajima, T., Kurano, M., Iida, H., Takano, H., Oonuma, H., Morita, T., et al. (2006). Use and safety of KAATSU training: results of a national survey. Int. J. Kaatsu Train. Res. 2, 5-13. doi: 10.3806/ijktr.2.5

Norsk, P. (2014). Blood pressure regulation IV: adaptive responses to weightlessness. Eur. J. Appl. Physiol. 114, 481-497. doi: 10.1007/s00421013-2797-2

Ozaki, H., Abe, T., Mikesky, A. E., Sakamoto, A., Machida, S., and Naito, H. (2015). Physiological stimuli necessary for muscle hypertrophy. J. Phys. Fit. Sports Med. 4, 43-51. doi: 10.7600/jpfsm.4.43

Park, S.-Y., Kwak, Y. S., Harveson, A., Weavil, J. C., and Seo, K. E. (2015). Low intensity resistance exercise training with blood flow restriction: insight into cardiovascular function, and skeletal muscle hypertrophy in humans. Korean J. Physiol. Pharmacol. 19, 191-196. doi: 10.4196/kjpp.2015.19.3.191

Pearson, S. J., and Hussain, S. R. (2015). A review on the mechanisms of bloodflow restriction resistance training-induced muscle hypertrophy. Sports Med. 45, 187-200. doi: 10.1007/s40279-014-0264-9

Pope, Z. K., Willardson, J. M., and Schoenfeld, B. J. (2013). Exercise and blood flow restriction. J. Strength Cond. Res. 27, 2914-2926. doi: 10.1519/JSC. 0b013e3182874721

Qin, Y.-X., Kaplan, T., Saldanha, A., and Rubin, C. (2003). Fluid pressure gradients, arising from oscillations in intramedullary pressure, is correlated with the formation of bone and inhibition of intracortical porosity. J. Biomech. Bone Cell Tissue Mech. 36, 1427-1437. doi: 10.1016/S0021-9290(03)00127-1

Renzi, C. P., Tanaka, H., and Sugawara, J. (2010). Effects of leg blood flow restriction during walking on cardiovascular function. Med. Sci. Sports Exerc. 42, 726-732. doi: 10.1249/MSS.0b013e3181bdb454

Robling, A. G., Hinant, F. M., Burr, D. B., and Turner, C. H. (2002a). Improved bone structure and strength after long-term mechanical loading is greatest if loading is separated into short bouts. J. Bone Miner. Res. 17, 1545-1554. doi: $10.1359 /$ jbmr.2002.17.8.1545 
Robling, A. G., Hinant, F. M., Burr, D. B., and Turner, C. H. (2002b). Shorter, more frequent mechanical loading sessions enhance bone mass. Med. Sci. Sports Exerc. 34, 196-202.

Rochefort, G. Y., and Benhamou, C. L. (2013). Osteocytes are not only mechanoreceptive cells. Int. J. Numer. Methods Biomed. Eng. 29, 1082-1088. doi: $10.1002 / \mathrm{cnm} .2561$

Rozales Ramis, T., da Silva Medeiros, N., de Lemos Muller, C. H., Boeno, F., Silveira, D., Souza, L. G., et al. (2017). Effects of acute exercise with blood flow restriction on oxidative stress biomarkers. Int. J. Sports Sci. 7, 191-195. doi: $10.5923 /$ j.sports. 20170705.03

Sawin, C. F., Nicogossian, A. E., Rummel, J. A., and Michel, E. L. (1976). Pulmonary function evaluation during the skylab and apollo-soyuz missions. Aviat. Space Environ. Med. 47, 168-172.

Saxon, L. K., Robling, A. G., Alam, I., and Turner, C. H. (2005). Mechanosensitivity of the rat skeleton decreases after a long period of loading, but is improved with time off. Bone 36, 454-464. doi: 10.1016/j.bone.2004.12.001

Scheuring, R. A., Mathers, C. H., Jones, J. A., and Wear, M. L. (2009). Musculoskeletal injuries and minor trauma in space: incidence and injury mechanisms in U.S. Astronauts. Aviat. Space Environ. Med. 80, 117-124. doi: 10.3357/ASEM.2270.2009

Schoenfeld, B. J. (2010). The mechanisms of muscle hypertrophy and their application to resistance training. J. Strength Cond. Res. 24, 2857-2872. doi: 10.1519/JSC.0b013e3181e840f3

Schoenfeld, B. J. (2013). Is there a minimum intensity threshold for resistance training-induced hypertrophic adaptations? Sports Med. 43, 1279-1288. doi: 10.1007/s40279-013-0088-z

Schoenfeld, B. J., and Contreras, B. (2014). The muscle pump: potential mechanisms and applications for enhancing hypertrophic adaptations. Strength Cond. J. 36, 21-25. doi: 10.1097/SSC.0000000000000021

Scott, B. R., Slattery, K. M., Sculley, D. V., and Dascombe, B. J. (2014). Hypoxia and resistance exercise: a comparison of localized and systemic methods. Sports Med. 44, 1037-1054. doi: 10.1007/s40279-014-0177-7

Sibonga, J. D., Cavanagh, P. R., Lang, T. F., LeBlanc, A. D., Schneider, V. S., Shackelford, L. C., et al. (2007). Adaptation of the skeletal system during longduration spaceflight. Clin. Rev. Bone Miner. Metab. 5, 249-261. doi: 10.1007/ s12018-008-9012-8

Snijders, T., Nederveen, J. P., Joanisse, S., Leenders, M., Verdijk, L. B., van Loon, L. J. C., et al. (2017). Muscle fibre capillarization is a critical factor in muscle fibre hypertrophy during resistance exercise training in older men. J. Cachexia Sarcopenia Muscle 8, 267-276. doi: 10.1002/jcsm. 12137

Spurway, N., and Wackerhage, H. (2006). Genetics and Molecular Biology of Muscle Adaption: Advances in Sport and Exercise Science Series, 1st Edn. Edinburgh: Elsevier.

Stevens, H. Y., Meays, D. R., and Frangos, J. A. (2006). Pressure gradients and transport in the murine femur upon hindlimb suspension. Bone 39, 565-572. doi: 10.1016/j.bone.2006.03.007

Takada, S., Okita, K., Suga, T., Omokawa, M., Kadoguchi, T., Sato, T., et al. (2012). Low-intensity exercise can increase muscle mass and strength proportionally to enhanced metabolic stress under ischemic conditions. J. Appl. Physiol. 113, 199-205. doi: 10.1152/japplphysiol.00149.2012

Takano, H., Morita, T., Iida, H., Asada, K. I., Kato, M., Uno, K., et al. (2005). Hemodynamic and hormonal responses to a short-term low-intensity resistance exercise with the reduction of muscle blood flow. Eur. J. Appl. Physiol. 95, 65-73. doi: 10.1007/s00421-005-1389-1

Thiebaud, R. S., Yasuda, T., Loenneke, J. P., and Abe, T. (2013). Effects of lowintensity concentric and eccentric exercise combined with blood flow restriction on indices of exercise-induced muscle damage. Interv. Med. Appl. Sci. 5, 53-59. doi: 10.1556/IMAS.5.2013.2.1

Trappe, S., Costill, D., Gallagher, P., Creer, A., Peters, J. R., Evans, H., et al. (2009). Exercise in space: human skeletal muscle after 6 months aboard the international space station. J. Appl. Physiol. 106, 1159-1168. doi: 10.1152/ japplphysiol.91578.2008

Tsutsumi, Y. M., Yokoyama, T., Horikawa, Y., Roth, D. M., and Patel, H. H. (2007). Reactive oxygen species trigger ischemic and pharmacological postconditioning: in vivo and in vitro characterization. Life Sci. 81, 1223-1227. doi: 10.1016/j.lfs.2007.08.031

Vanderby, R. Jr., Vailas, A. C., Graf, B. K., Thielke, R. J., Ulm, M. J., Kohles, S. S., et al. (1990). Acute modification of biomechanical properties of the boneligament insertion to rat limb unweighting. FASEB J. 4, 2499-2505. doi: 10. 1096/fasebj.4.8.2335272

Vernikos, J., and Schneider, V. S. (2010). Space, gravity and the physiology of aging: parallel or convergent disciplines? A mini-review. Gerontology 56, 157-166. doi: $10.1159 / 000252852$

Wernbom, M., Paulsen, G., Nilsen, T. S., Hisdal, J., and Raastad, T. (2012). Contractile function and sarcolemmal permeability after acute low-load resistance exercise with blood flow restriction. Eur. J. Appl. Physiol. 112, 20512063. doi: 10.1007/s00421-011-2172-0

Widrick, J. J., Knuth, S. T., Norenberg, K. M., Romatowski, J. G., Bain, J. L. W., Riley, D. A., et al. (1999). Effect of a 17 day spaceflight on contractile properties of human soleus muscle fibres. J. Physiol. 516(Pt 3), 915-930. doi: 10.1111/j. 1469-7793.1999.0915u.x

Yang, R.-S., Lin, W. L., Chen, Y. Z., Tang, C. H., Huang, T. H., Lu, B. Y., et al. (2005). Regulation by ultrasound treatment on the integrin expression and differentiation of osteoblasts. Bone 36, 276-283. doi: 10.1016/j.bone.2004. 10.009

Yow, B. G., Tennent, D. J., Dowd, T. C., Loenneke, J. P., and Owens, J. G. (2018). Blood flow restriction training after achilles tendon rupture. J. Foot Ankle Surg. 57, 635-638. doi: 10.1053/j.jfas.2017.11.008

Zhang, J., and Wang, J. H.-C. (2013). Human tendon stem cells better maintain their stemness in hypoxic culture conditions. PLoS One 8:e61424. doi: 10.1371/ journal.pone.0061424

Zhao, J., Zhang, P., Qin, L., and Pan, X. H. (2011). Hypoxia is essential for bonetendon junction healing: the molecular biological evidence. Int. Orthop. 35 925-928. doi: 10.1007/s00264-010-1157-7

Conflict of Interest Statement: The authors declare that the research was conducted in the absence of any commercial or financial relationships that could be construed as a potential conflict of interest.

Copyright (c) 2019 Behringer and Willberg. This is an open-access article distributed under the terms of the Creative Commons Attribution License (CC BY). The use, distribution or reproduction in other forums is permitted, provided the original author(s) and the copyright owner(s) are credited and that the original publication in this journal is cited, in accordance with accepted academic practice. No use, distribution or reproduction is permitted which does not comply with these terms. 